7. Roundaut R, Labbe T, Lorient Roudaunt MF. Mechanical cardiac valve thrombosis: is fibrinolysis justified? Circulation 1992; 86 (Supl. 2): 815 .

8. Özkan M, Kaymaz C, Kirma C, Sönmez K, Ózdemir N, Balkanay M, et al. Intravenous thrombolytic treatment of mechanic valve trombosis: A study using serial transesophageal echocardiography. J Am Coll Cardiol 2000; 35: 1881-9.

9. Lengyel M. Management of prosthetic valve trombosis. J Heart Valve Dis 2004; 13: 329-34.

10. ACC/AHA guidelines for the management of patients with valvular heart disease. A report of the American College of Cardiology/American Heart Association. Task Force on Practice Guidelines (Committee on Management of Patients with Valvular Heart Disease). J Am Coll Cardiol 1998; 32 (5): 1486-588

\section{Fiebre de origen desconocido y líquen plano en pene}

\section{Sr. Director:}

La enfermedad de Crohn es una patología inflamatoria crónica intestinal cuya forma de presentación más frecuente es la aparición de episodios de dolor abdominal, diarrea y pérdida ponderal. En otras ocasiones puede comenzar como un cuadro más larvado, con sintomatología inespecífica, con las complicaciones características de la enfermedad, tanto del tracto gastrointestinal como de otras partes del cuerpo, o con manifestaciones extraintestinales. Presentamos un caso de aparición atípica de la enfermedad, cuya clínica inicial consistió únicamente en episodios repetidos de fiebre de origen desconocido y en el que la evolución y la indagación exhaustiva de los antecedentes personales y familiares fueron determinantes para su diagnóstico.

Varón de 36 años diagnosticado de liquen plano 7 años antes, que afectaba a extremidades y al pene, con múltiples recidivas. Estaba siendo estudiado ambulatoriamente desde hacía 8 meses por episodios de fiebre intermitente, autolimitados, de unos 3 días de duración, de hasta $40{ }^{\circ} \mathrm{C}$, sin focalidad y que habían comenzado un año antes de acudir a la consulta. Desde el inicio de su proceso había presentado varios flemones bucales atribuidos a caries y un episodio de parálisis facial periférica idiopática, resuelto. Actualmente se encontraba con debilidad del hombro derecho e incapacidad para la abducción de esa extremidad, siendo diagnosticado de "escápula alada". En el momento actual ingresó en el servicio de medicina interna por un nuevo episodio de fiebre de $38^{\circ} \mathrm{C}$ y dolor abdominal difuso, tipo cólico, acompañado de una deposición blanda. El paciente refería en los días previos empeoramiento de las lesiones del pene, con despeños diarreicos desde hacía meses, coincidiendo con el comienzo de la fiebre y alguna rectorragia de escasa cuantía en las últimas semanas.

En la exploración abdominal destacaba la palpación del polo inferior del bazo. En el pene tenía unas úlceras lineales con base eritematosa, y muy dolorosas al tacto. También existía limitación para la abducción del miembro superior derecho.

De las pruebas realizadas en la consulta disponíamos de un EMG del miembro superior derecho con afectación del nervio supraescapular y del torácico largo, bien por desmielinización o por compresión. Una TAC abdominal con esplenomegalia homogénea. Una IgM positiva para CMV (coincidente con la aparición de la escápula alada), infección pasada para Epstein Barr, anti HBs positivo. VIH, VHC, ricketsias, mantoux, lues, aglutinaciones brucella y salmonella fueron negativos. ANAs negativos. En el ingreso actual destacaba un hemograma y bioquímica con perfil renal y hepático normal. PCR 77. Proteinograma con leve aumento de alfa1, alfa2. Beta 2 microglobulina elevada. En la orina no había alteraciones. Los hemocultivos fueron negativos. Serología a Leishmania en orina negativa. RX Tórax y Abdomen: normal. El estudio de RM del plexo braquial derecho no mostraba alteraciones en la morfología e intensidad de señal de las estructuras, sin lesión ocupante de espacio, o signos inflamatorios de las fibras nerviosas. En la eco abdominal: Esplenomegalia homogénea.

Hasta que el paciente ingresó no había mencionado, en ningún momento, la coincidencia de la fiebre con los despeños diarreicos y solo lo hizo cuando fue preguntado expresamente sobre ello. Tampoco teníamos información sobre los antecedentes familiares, que en este caso nos ayudaron, en gran medida, al diagnóstico final, al conocer la existencia de un hermano afecto de enfermedad inflamatoria intestinal (EII). Por todo ello realizamos una colonoscopia observando un área ulcerada a los $15 \mathrm{~cm}$ del ano, de la que se tomaron biopsias cuyos resultados dieron datos de inflamación aguda y crónica, siendo el resto del colon normal con biopsias sin alteraciones. Se consiguió penetrar en ileon distal y a pesar de la mala visualización se tomó una biopsia de una ulceración aftoide, obteniendo en la muestra tejido de granulación e inflamación aguda. Decidimos completar el estudio con un transito gastrointestinal (Fig. 1) donde se objetivó un estrechamiento del tramo final del intestino delgado (signo de la cuerda) con úlceras múltiples y pseudopólipos compatible con enfermedad de Crohn. El Servicio de Dermatología confirmó que las lesiones del pene eran un brote de liquen plano con esclerosis, por el que el servicio de Urología realizó cirugía por parafimosis. Se inició tratamiento con corticoides y mesasalazina. En las revisiones posteriores el paciente se encuentra estable y fue tratado por el servicio de rehabilitación de la afección del miembro superior derecho, con normalización de la movilidad.

La enfermedad de Crohn, aunque no sea lo habitual, puede manifestarse como una fiebre de origen desconocido y sin una clínica gastroenterológica clara, al menos en su comienzo $(1,2)$. Es por ello que ha de estar presente en nuestro diagnóstico diferencial cuando un paciente es estudiado por esta causa (3). Es frecuente la relación de la EII con procesos cutáneos, siendo los más conocidos el pioderma gangrenoso y el eritema nodoso. Se revisó la bibliografía buscando relación entre la enfermedad de Crohn y el

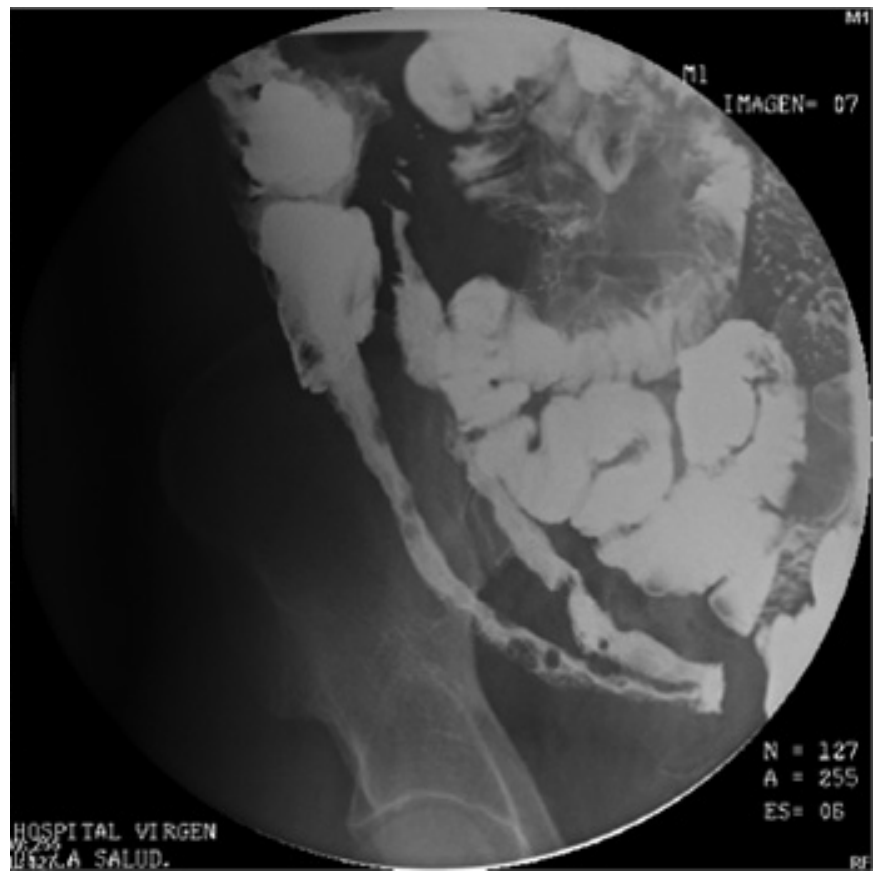

Fig. 1. Tránsito gastrointestinal. 
liquen plano y se encontró asociación entre ellos, siendo éste persistente e independiente de la evolución intestinal, a diferencia del eritema nodoso que refleja la actividad de la EII $(4,5)$.

Los abscesos flemonosos orales que ha padecido nuestro paciente parecen estar relacionados con caries dentales, aunque no podemos descartar que hubieran sido favorecidos por la predisposición que tienen los enfermos de Crohn para desarrollar este tipo de patologías (6).

En relación con la neuritis está descrita la afectación sensitivo motora por CMV, siendo además característica la afectación de los nervios del plexo braquial (7). La infección por CMV es frecuente en la EII complicada y refractaria a tratamiento esteroideo (8). Se relaciona más frecuentemente con pacientes inmunocomprometidos, como VIH, receptores de trasplantes o en tratamiento corticoideo, como nuestro paciente que los había recibido para el tratamiento del liquen. Cada vez hay un mayor número de autores que afirman que el CMV influye en el curso clínico de la E.I.I. y que agrava las agudizaciones, debiendo pensar en ello siempre que el episodio sea complicado y refractario a los corticoides $(9,10)$. Se da con mayor frecuencia en la colitis que en el Crohn, llegando a porcentajes mayores del veinte por cien en las colitis ulcerosas que requieren tratamiento quirúrgico. Otras posibilidades que podrían explicar la afección de los nervios podría ser la deficiencia de vitamina B12 o del complejo B, por malabsorción, debida a la alteración del ileon terminal, pero en este paciente los valores resultaron normales.

Hemos de resaltar la importancia de una buena historia clínica, con una minuciosa anamnesis, y sin dejar de lado los antecedentes tanto personales como familiares, que en muchas ocasiones nos dan la pista diagnóstica.

\section{E. Rubio Hidalgo, G. Muñiz Nicolás, A. Alguacil Muñoz, E. Ortiz Ortiz, A. Tutor Martínez}

Servicio de Medicina Interna. Hospital Virgen de la Salud. Toledo

1. Erten N, Saka B, Ozturk G, Karan MA, Tascioglu C, Dilmener M, Kaysi A. Fever of unknown origin: A report of 57 cases. Int J Clin Pract 2005; 59: 958-60

2. Lonardo A, Tondelli E, Selmi I, Bagni A, Della Casa G, Grisendi A. Isolated jejunal Crohn's disease in a young adult presenting as fever of unknown origin. Am J Gastroenterol 1998; 93: 2285-7.

3. Domínguez A, Pena JM, Barbado FJ, González JJ, del Arco A, Vázquez JJ. Prolonged course fever as presentation form of Crohn's disease. An Med Interna (Madrid) 1990; 7: 39-41.

4. Rosen T, Brown TJ. Genital ulcers. Evaluation and treatment. Dermatol Clin 1998; 16: 673-85.

5. Kano Y, Shiohara T, Yagita A. Erythema nodosum, lichen planus and lichen nitidus in Crohn disease: Report of case and analysis of $\mathrm{T}$ cell receptor $\mathrm{V}$ gene expression in the cutaneus and intestinal lesions. Dematology 1995; 190: 59-63.

6. Gagoh OK, Qureshi RM, Hendrickse MT. Recurrent buccal space abscesses: A complication of Crohn's disease. Oral Surg Oral Med Oral Pathol Oral Radiol Endod 1999; 88: 33-6.

7. Duchowny M, Caplan L, Siber G. Cytomegalovirus infection of the adult nervous system. Ann Neurol 1979; 5: 458

8. Cottone M , Pietrosi G, Martorana G. Prevalence of CMV infection in severe refractory ulcerative and Crohn's colitis. Am J Gastroenterol 2001; 96: 773-5

9. Coban S, Ensari A, Kuzu MA, Yalcin S, Palabiyikoglu M, Ormeci N. Cytomegalovirus infection in a patient with Crohn's ileocolitis. Can J Gastroenterol 2005; 19: 109-11.

10. Hommes DW, Sterringa G, van Deventer SJ, Tytgat GN, Weel J. The pathogenicity of cytomegalovirus in inflammatory bowel disease: A systematic review and evidence-based recommendations for future research. Inflamm Bowel Dis 2004; 10: 245-50

\section{Fiebre sin foco en paciente con dolor crónico}

\section{Sr. Director:}

El uso durante tiempo prolongado de catéteres centrales, para el tratamiento de múltiples patologías tan extendido en la actualidad, conlleva una serie de riesgos y de complicaciones en los pacientes. Existen casos descritos en la literatura en los que su uso se relaciona con el desarrollo de endocarditis, con una gran morbi-mortalidad, así como un gran coste sanitario. Presentamos a continuación el caso de una paciente portadora de un catéter central para tratamiento de dolor crónico que desarrolla una endocarditis sobre la punta del mismo.

Se trata de una mujer de 35 años con síndrome de Ehler-Danlos tipo II, crioglobulinemia mixta tipo II, ingresos previos por bacteriemia por Pseudomonas aeruginosa, y dolor osteo-articular crónico en relación con luxación recidivante de articulaciones, tratada en la Unidad del Dolor con perfusión de mórficos mediante reservorio en vena cava superior.

Se remite desde esta Unidad para su ingreso en Medicina Interna por un cuadro de cinco días de evolución de fiebre de hasta $41{ }^{\circ} \mathrm{C}$, tos y bacteriemia por Streptococcus mitis. Al ingreso la paciente presenta una temperatura de $39,5^{\circ} \mathrm{C}$ y una frecuencia cardiaca de $115 \mathrm{lpm}$, destacando en la exploración física la presencia de un soplo sistólico en foco aórtico. En el hemograma se objetiva 19.800 leucocitos (91,8\% neutrófilos, 3,7\% linfocitos, $24 \%$ cayados); la orina es normal. En el ECG se muestra una taquicardia sinusal a 109 lpm, y en la radiografía de tórax no se observan signos de patología pleuropulmonar aguda. Para completar el estudio de fiebre sin foco se solicita un ecocardiograma visualizándose el catéter en $\mathrm{AD}$ con masa muy móvil en su punta. Se corrobora el hallazgo mediante la realización de un ecocardiograma transesofágico, en donde se observa una imagen compatible con vegetación de unos $50 \mathrm{~mm}$ de largo y $10 \mathrm{~mm}$ de grosor (Fig. 1)

Al llegar a nuestro servicio se pauta vancomicina y gentamicina según protocolo de endocarditis y de acuerdo con antibiograma. Se le realiza un TC craneal y tóraco-abdómino-pélvico descartándose abscesos sépticos periféricos. Ante el tamaño de la vegetación se comenta el caso con el Servicio de Cirugía Cardiaca, que recomiendan exéresis quirúrgica mediante auriculotomía derecha, siendo la intervención un éxito. Estando la paciente con buen estado general, y esperando el tiempo oportuno tras la cirugía para completar tratamiento antibiótico i.v., se decide el alta hospitalaria.

El Streptococcus mitis pertenece al grupo viridans que comprende un grupo heterogéneo de especies que forman parte de la

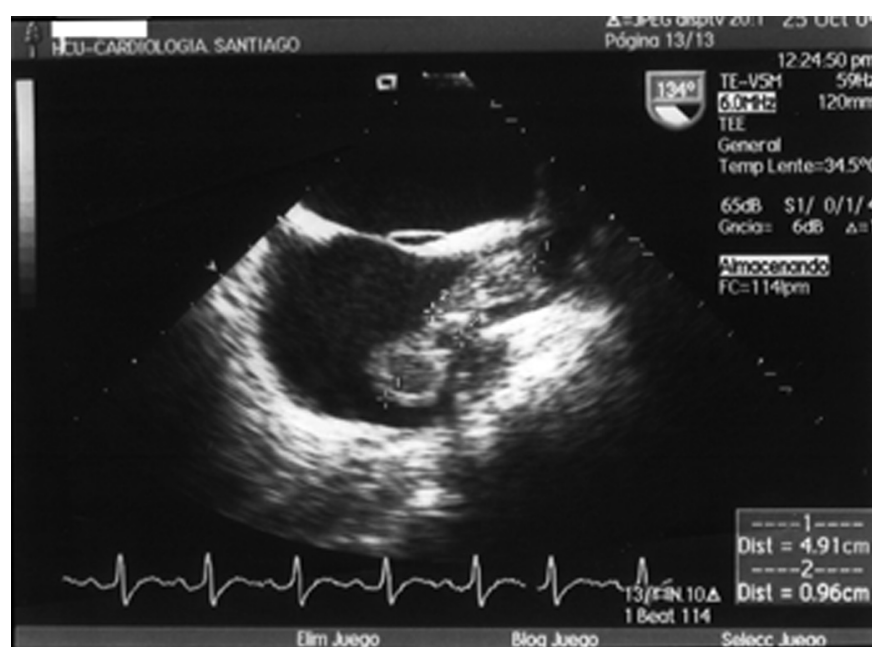

Fig. 1. Masa móvil en punta de catéter. 